\title{
Simvastatin attenuates TNF- $\alpha$-induced apoptosis in endothelial progenitor cells via the upregulation of SIRT1
}

\author{
GANG DU $^{1 *}$, YUNLIN SONG $^{2 *}$, TAO ZHANG $^{1}$, LONG MA $^{2}$, NING BIAN $^{1}$, \\ XIAOMING CHEN $^{1}$, JIANYI FENG ${ }^{1}$, QING CHANG ${ }^{3}$ and ZICHENG LI ${ }^{1}$ \\ ${ }^{1}$ Department of Internal Medicine, The First Affiliated Hospital of Jinan University, Guangzhou 510630; \\ ${ }^{2}$ Intensive Care Unit, The First Affiliated Hospital of Xinjiang Medical University, Urumqi 830011; \\ ${ }^{3}$ Department of Histology and Embryology, Medical College of Jinan University, Guangzhou 510632, P.R. China
}

Received February 6, 2014; Accepted April 1, 2014

DOI: $10.3892 / \mathrm{ijmm} .2014 .1740$

\begin{abstract}
Endothelial progenitor cells (EPCs) originate from the bone marrow and can be classified as either early or late EPCs. The focus of this study was on late EPCs, as they play an important role in angiogenesis and vascular proliferation. Evidence suggests that inflammatory and oxidative changes can increase EPC apoptosis. Of note, tumor necrosis factor- $\alpha(\mathrm{TNF}-\alpha)$ is a contributing risk factor to the development of atherosclerosis and plays a key role as both an inflammatory mediator and an inducer of apoptosis in endothelial cells. Additionally, a member of the sirtuin family, silent information regulator type-1 (SIRT1), promotes cell survival by repressing p53- and non-p53-dependent apoptosis in response to DNA damage and oxidative stress. Statins have also been shown to play a key role in the prevention of endothelial apoptosis and senescence via their lipid-lowering and anti-inflammatory actions. However, there is little evidence that statins themselves attenuate EPC apoptosis induced by TNF- $\alpha$. The aim of this study was to demonstrate the effectiveness of one of the most commonly used statins, simvastatin, on decreasing TNF- $\alpha$-induced apoptosis in EPCs. The results indicated that SIRT1 protein expression was decreased by TNF- $\alpha$ in a time- and dose-dependent manner and that while TNF- $\alpha$ caused a marked increase in the percentage of apoptotic EPCs, application of simvastatin decreased this percentage. A high concentration of simvastatin promoted the expression of SIRT1 and increased the proliferation of EPCs. In conclusion, findings of this study showed that simvastatin is crucial in
\end{abstract}

Correspondence to: Professor Zicheng Li, Department of Internal Medicine, The First Affiliated Hospital of Jinan University, No. 613 Huangpu Road, Guangzhou 510630, P.R. China

E-mail: zichengli@163.net

${ }^{*}$ Contributed equally

Key words: endothelial progenitor cells, tumor necrosis factor- $\alpha$, silent information regulator type-1, simvastatin, apoptosis counteracting the TNF- $\alpha$-induced apoptosis of EPCs and that this protection may involve the actions of SIRT1.

\section{Introduction}

Endothelial progenitor cells (EPCs) originate in the bone marrow. They are recruited into peripheral circulation in response to tissue ischemia or back to their site of origin to areas of injured endothelium. In this manner, they participate in the repair of damaged tissues, thereby improving blood flow and attenuating the progression of atherosclerosis (1). Since both animal models and human studies have shown that EPCs can contribute to neovascularization and re-endothelialization, EPCs have been examined as potential treatments for various types of ischemic disease, including stroke (2), ischemic myocardium $(3,4)$, kidney injury $(5)$, and ischemic vascular disease (6). Moreover, it has been reported that a low EPC level is an independent risk factor for future cardiovascular events such as unstable angina and myocardial infarction (MI) $(7,8)$. MI (9) and limb ischemia $(10,11)$ themselves have been associated with an increase in circulating EPC numbers, and vascular traumas such as acute MI with ST elevation (12) and percutaneous coronary intervention (13) have been suggested to induce the rapid mobilization of EPCs.

Evidence from in vitro and clinical studies suggested that inflammatory and oxidative changes can influence EPC apoptosis $(14,15)$. Additionally, tumor necrosis factor- $\alpha$ (TNF- $\alpha$ ) is a contributing risk factor in atherosclerosis and common metabolic disturbances including insulin resistance and dyslipidemia (16). More specifically, TNF- $\alpha$ plays a key role as both an inflammatory mediator and inducer of apoptosis in endothelial cells $(17,18)$. Evidence of these roles can be found in the increased plasma levels of TNF- $\alpha$ in diabetic patients, which have been shown to impair the function of endothelial cells, as well as to enhance their aging and apoptosis (19-21). A previous in vitro study has shown that incubation of EPCs with TNF- $\alpha$ increases p38-phosphorylation, resulting in a reduction of total EPCs (22). Clinically, statins are widely used in the treatment of dyslipidemia and associated vascular abnormalities. In fact, clinical trials with statins have shown considerable benefits in patients with ischemic heart and peripheral disease, irrespective of their cholesterol 
concentration (23). Evidence from in vitro and in vivo data have demonstrated that statins exert pleiotropic actions beyond their lipid-lowering effects, including immune regulation, anti-inflammatory effects, maintenance of plaque stability, and anti-platelet effects, in addition to anti-fibrotic and anti-oxidant properties (24-27).

Silent information regulator type-1 (SIRT1) is a member of the sirtuin family of nicotinamide adenine dinucleotide (NAD)-dependent class III histone deacetylases (HDACs). Previous studies have shown that SIRT1 promotes cell survival by repressing p53-dependent apoptosis in response to DNA damage and oxidative stress. This repression occurs via physical interaction with both $\mathrm{p} 53$ and the forkhead transcription factor (FOXO) family of proteins (28-30). Additionally, evidence suggests that SIRT1 may be involved in pathways of telomere maintenance, giving them a putative role in aging and survival (31). It has been reported that statins can activate SIRT1, which raises the possibility of their epigenetic regulation of inflammatory responses. Moreover, SIRT1 plays a key role in the prevention of endothelial apoptosis and senescence through its direct effect on endothelial nitric oxide synthase (eNOS) activation $(32,33)$. However, there is little evidence that statins can attenuate TNF- $\alpha$-induced apoptosis in EPCs. Furthermore, the possible anti-apoptotic effects of SIRT1 are currently unclear.

Thus, the present study aimed to clarify the roles of statin application and activation of SIRT1 on EPC apoptosis. The results showed that simvastatin, one of the most commonly used statins, is capable of reducing TNF- $\alpha$-induced apoptosis in EPCs, and that SIRT1 may play a critical role in the prevention of EPC apoptosis.

\section{Materials and methods}

Materials. TNF- $\alpha$ was obtained from PeproTech, Inc. (Rocky Hill, NJ, USA). 3-(4,5-Dimethylthiazol-2-yl)-2,5- diphenyltetrazolium bromide (MTT) was purchased from Sigma-Aldrich (St. Louis, MO, USA). SIRT1 antibody was obtained from Cell Signaling Technology, Inc. (Beverly, MA, USA). The FITC Annexin V Apoptosis Detection kit was purchased from BD Pharmingen (San Diego, CA, USA). EGM-2MV was obtained from Clonetics (San Diego, CA, USA), Lymphoprep ${ }^{\text {TM }}$ was purchased from Axis-shield (Oslo, Norway), and Matrigel from BD Biosciences (San Diego, CA, USA).

Cell culture. EPCs derived from human umbilical cord blood were obtained by Lymphoprep ${ }^{\mathrm{TM}}$ density gradient centrifugation at $800 \mathrm{x} \mathrm{g}$, for $20 \mathrm{~min}$ at a temperature of $4^{\circ} \mathrm{C}$. Following centrifugation, the mononuclear cells (MNCs) layer was harvested and washed twice in $0.9 \%$ saline. The MNCs were cultivated in endothelial differentiation medium (EGM-2MV), which contained $5 \%$ fetal bovine serum, VEGF, fibroblast growth factor-2, epidermal growth factor, insulin-like growth factor-1 and ascorbic acid. Cell cultures were maintained at $37^{\circ} \mathrm{C}$ with $5 \% \mathrm{CO}_{2}$ and $21 \% \mathrm{O}_{2}$ in a humidified atmosphere. Three days after plating, the non-adherent cells were discarded and fresh medium was applied. To maintain optimal culture conditions, the medium was changed on alternate days. The cells were selected for in vitro study after three total passages.
Western blot analysis. EPCs were homogenized in phosphate-buffered saline containing a protease inhibitor cocktail (50 mM Tris, pH 7.6, $150 \mathrm{mM} \mathrm{NaCl}, 1$ mM EDTA, $1 \%$ Triton $\mathrm{X}-100,0.5 \%$ sodium deoxycholate, $0.1 \%$ SDS, and $10 \%$ glycerol). The samples were incubated overnight at $4^{\circ} \mathrm{C}$ with rabbit anti-SIRT1 (1:500) (Cell Signaling Technology, Inc.). Antibody signal was detected using a Chemiluminescent Detection kit according to the manufacturer's protocol (Beyotime, Haimen, China). The results were normalized to GAPDH. The relative band intensities of the blots were determined with Adobe Photoshop software.

Apoptosis analysis. After treatment for $48 \mathrm{~h}$, EPCs were harvested, washed in ice-cold PBS, resuspended in $500 \mu \mathrm{l}$ of binding buffer, and incubated in the dark with $5 \mu \mathrm{l}$ of propidium iodide (PI) and $5 \mu 1$ of Annexin V-fluorescein isothiocyanate for $15 \mathrm{~min}$. The samples were washed and resuspended in $500 \mu \mathrm{l}$ PBS, before analyzing with flow cytometry.

MTT growth curve. EPCs were detached and seeded into 96-well plates (4,000 cells per well). At the indicated time-points (24, 48 and $72 \mathrm{~h}$ after culture), the cells were stained with MTT $(5 \mathrm{mg} / \mathrm{ml})$ in PBS for $3 \mathrm{~h}$, and then dissolved with $50 \%$ $\mathrm{N}, \mathrm{N}$-dimethylformamide and $10 \% \mathrm{SDS}$ for $3 \mathrm{~h}$ at $37^{\circ} \mathrm{C}$. The optical density at $570 \mathrm{~nm}$ was then determined. Each point was determined in triplicate and an average was obtained for analysis.

Tube formation assay. To demonstrate capillary tube formation, $250 \mu \mathrm{l}$ of Matrigel was added to 24-well plates and solidified for $30 \mathrm{~min}$ at $37^{\circ} \mathrm{C}$. EPCs were then seeded $\left(5 \times 10^{4}\right.$ cells/well) on the solidified Matrigel and suspended in $300 \mu \mathrm{l}$ of EGM2-MV medium. After 12- and 24-h incubations, the cells were incubated at $37^{\circ} \mathrm{C}$ with $5 \% \mathrm{CO}_{2}$ for 5-24 h.

Statistical analysis. Data are expressed as mean \pm SD. An unpaired Student's t-test was used to evaluate statistical differences between the groups. Differences were considered significant at a value of $\mathrm{P}<0.05$.

\section{Results}

TNF- $\alpha$ induces apoptosis and decreases SIRT1 expression of EPCs. To investigate whether SIRT1 expression could be regulated by TNF- $\alpha$ in EPCs, EPCs were treated with TNF- $\alpha(10,20$ and $40 \mathrm{ng} / \mathrm{ml})$ for $24 \mathrm{~h}$ and the expression of SIRT1 was determined by western blot analysis. We found that TNF- $\alpha$ reduced SIRT1 protein expression in EPCs in a concentration-dependent manner (Fig. 1A). We also studied the time course of SIRT1 expression in EPCs by treating EPCs with TNF- $\alpha(20 \mathrm{ng} / \mathrm{ml})$ for 12,24 and $36 \mathrm{~h}$. Our results showed that SIRT1 protein expression decreased in a time-dependent manner when compared with the control (Fig. 1B).

Simvastatin inhibits TNF- $\alpha$-induced-apoptosis of EPCs. EPCs were treated with TNF- $\alpha(20 \mathrm{ng} / \mathrm{ml})$ for $24 \mathrm{~h}$ and two groups of EPCs were then selected and treated with two concentrations of simvastatin $\left(10^{-7}\right.$ or $\left.10^{-8} \mathrm{~mol} / \mathrm{l}\right)$. Cell apoptosis was then evaluated via flow cytometry. The results showed that TNF- $\alpha$ 

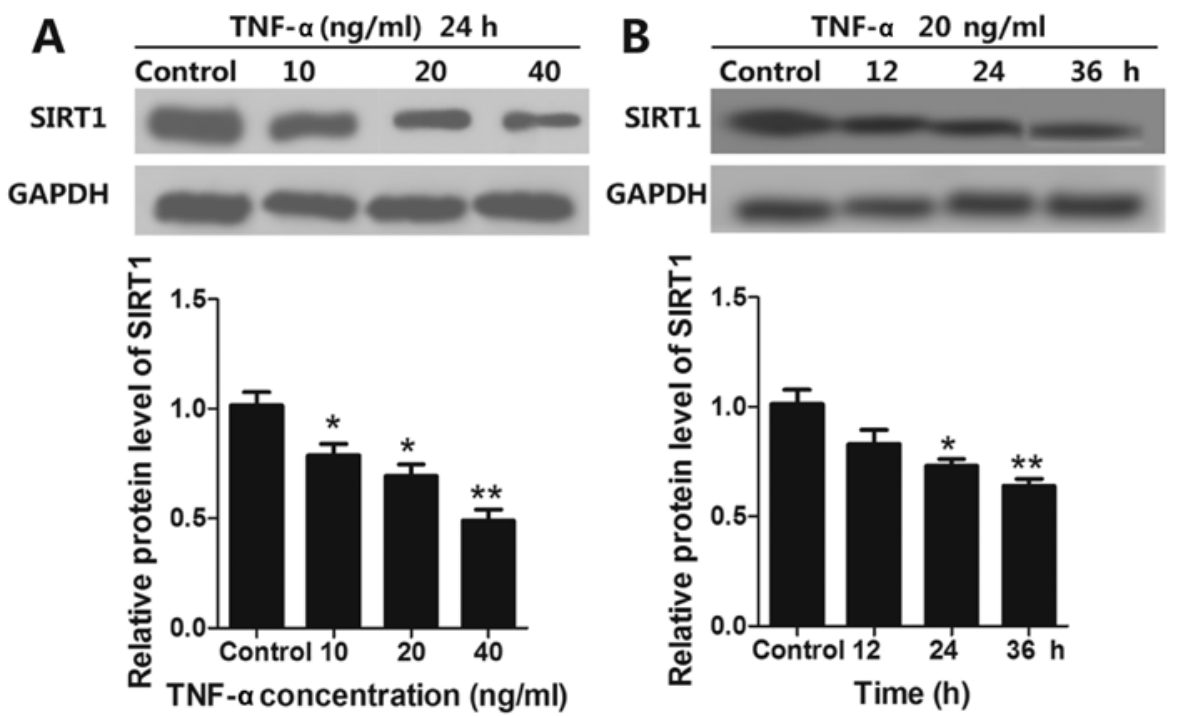

Figure 1. (A) Effects of tumor necrosis factor- $\alpha$ (TNF- $\alpha$ ) on silent information regulator type-1 (SIRT1) levels in endothelial progenitor cells (EPCs) is concentration- and time-dependent. EPCs were treated with TNF- $\alpha$ at concentrations of 10, 20, and $40 \mathrm{ng} / \mathrm{ml}$ for $24 \mathrm{~h}$ and SIRT1 expression was determined by western blot analysis. (B) EPCs were treated with TNF- $\alpha(20 \mathrm{ng} / \mathrm{ml})$ for the indicated time-points and SIRT1 expression was determined by western blot analysis. ${ }^{*} \mathrm{P}<0.05$ and $^{* *} \mathrm{P}<0.01$ compared to the control group, $\mathrm{n}=3$ for each group for western blot analysis.

caused a marked increase in the percentage of apoptotic EPCs. However, application of simvastatin decreased the number of apoptotic cells when compared with cells treated solely with TNF- $\alpha$. Moreover, we found that a higher concentration of simvastatin had a greater reduction in apoptotic cell number $(\mathrm{P}<0.05)$ (Fig. 2A and C).

Simvastatin increases TNF- $\alpha$-induced decreases in SIRTI levels. To investigate whether the TNF- $\alpha$-induced decrease of SIRT1 expression could be raised by simvastatin application, EPCs were treated with TNF- $\alpha$ and a high or low concentration simvastatin $\left(10^{-7}\right.$ or $\left.10^{-8} \mathrm{~mol} / \mathrm{l}\right)$. Expression of SIRT1 was then determined by western blot analysis. We found that a high concentration of simvastatin resulted in a marked increase in SIRT1 expression levels when compared to the TNF- $\alpha$-only group $(\mathrm{P}<0.05)$ (Fig. $2 \mathrm{~A}$ and $\mathrm{B})$. By contrast, we found that a low concentration of simvastatin resulted in a less obvious increase.

Simvastatin cannot restore the angiopoietic ability of TNF- $\alpha$-treated EPCs. The angiopoietic ability of simvastatin was assessed using the tube formation assay. We found that the angiopoietic ability of EPCs was significantly decreased by TNF- $\alpha(20 \mathrm{ng} / \mathrm{ml}, 24 \mathrm{~h})$. We also found that two different concentrations of simvastatin $\left(10^{-7}\right.$ or $\left.10^{-8} \mathrm{~mol} / \mathrm{l}\right)$ were not able to restore the angiopoietic ability of the EPCs.

Simvastatin promotes cell proliferation that was reduced by $T N F-\alpha$ application. The cell viability of EPCs was evaluated by an MTT assay. As shown in Fig. 3, the proliferation of EPCs treated with TNF- $\alpha(20 \mathrm{ng} / \mathrm{ml})$ was markedly inhibited when compared to the controls $(\mathrm{P}<0.01)$. High concentrations of simvastatin were able to partially enhance cell proliferation when compared to the TNF- $\alpha$-only group $(\mathrm{P}<0.05)$. No differences were observed in cell proliferation between the TNF- $\alpha$ group and low concentrations of simvastatin.

\section{Discussion}

EPCs are critical for angiogenesis in ischemic disease and inflammation. Numerous animal studies have suggested that the vaso- and atheroprotective effects of EPCs are associated with their cell replacement and non-cellular differentiation effects. These include trophic support and enhancement of the endogenous repair process $(3,34,35)$. EPCs are heterogeneous and can be classified into early or late EPCs. In ex vivo culture systems, early EPCs appear within 4-7 days, while late EPCs develop after 2-3 weeks. It has been hypothesized that early EPCs may primarily provide trophic support, while late EPCs, which express a variety of endothelial markers, differentiate into mature endothelial cells and contribute to vascular repair (36). Considerable evidence indicates that a reduction in the number of EPCs predicts future cardiovascular events. Thus, enhancement of the number of EPCs is of potential therapeutic benefit to individuals with cardiovascular diseases. In this study, late EPCs were selected as our subject due to their role in angiogenesis and proliferation (37).

Statins are beneficial for atherosclerosis via mechanisms independent of their lipid-lowering ability. For instance, increased EPC levels in the early post-infarction phase by statin treatment were associated with improved cardiac function and increased capillary density in the peri-infarct area after a MI (38). A number of mechanisms have been suggested by which statins may attenuate atherosclerosis disease and cellular senescence in EPCs. Several of these mechanisms involve the ability of statin therapy to enhance bone marrow VEGF protein levels, their ability to phosphorylate Akt, eNOS activity, and their ability to decrease oxidative DNA damage and prevent telomere shortening due to oxidative stress in EPCs (38-40). As a powerful factor in inflammatory stimulation, TNF- $\alpha$ has been reported to induce apoptosis and senescence of EPCs both in vitro and in vivo. However, there are no previous studies focusing on the ability of statins to 

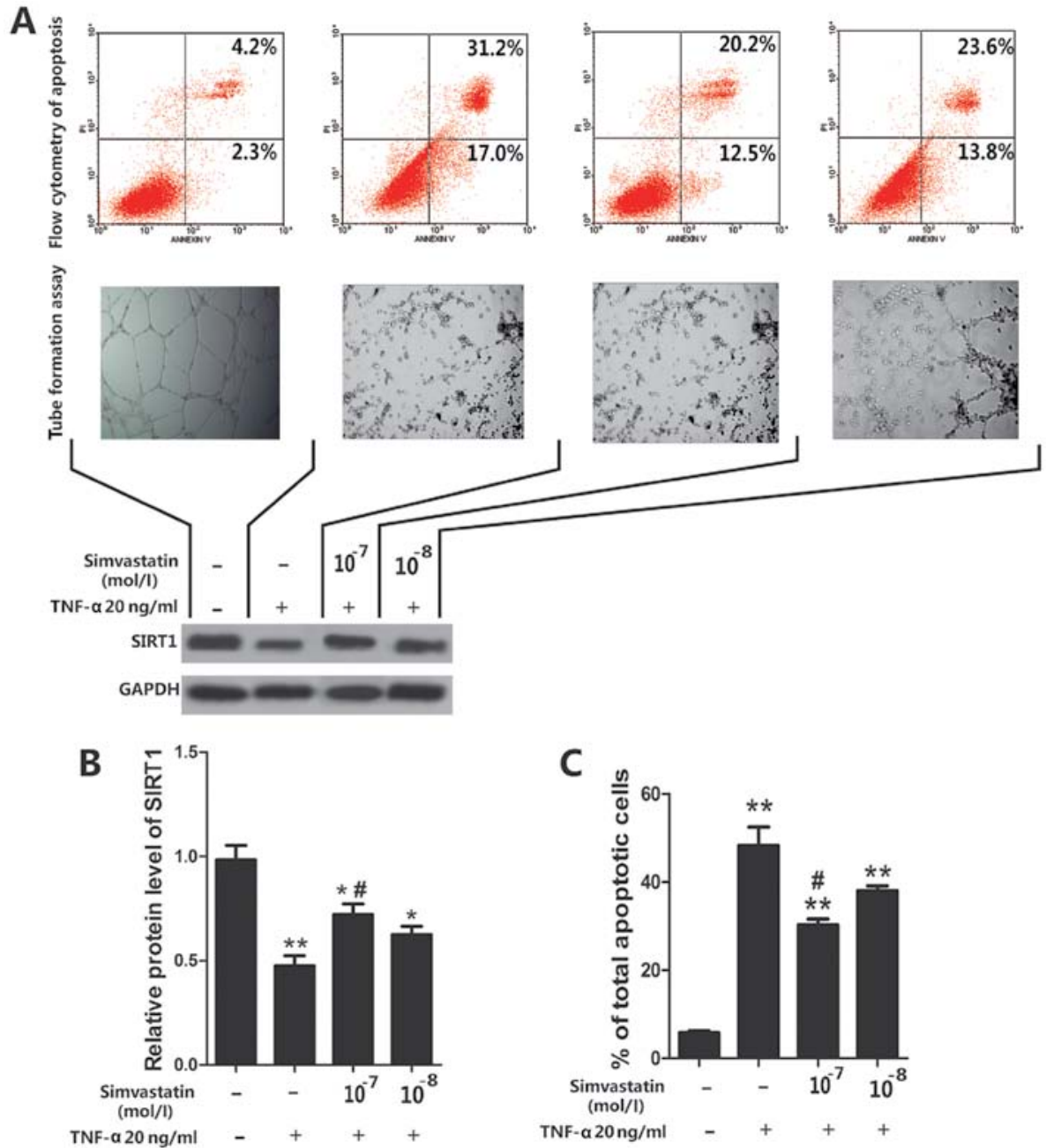

Figure 2. Effect of tumor necrosis factor- $\alpha$ (TNF- $\alpha$ ) and simvastatin on apoptosis and angiogenesis in endothelial progenitor cells (EPCs). (A) Cells were stained with both Annexin V/propidium iodide (PI) dual and analyzed by flow cytometry to determine the cell population in early and late apoptosis. Left lower quadrant, viable cells; right lower quadrant, early apoptotic cells; right upper quadrant, late apoptotic cells. (B and C) The total percentage of apoptotic cells within each treatment group is shown in the bar diagram. An in vitro study was used to examine tube formation as a function of TNF- $\alpha$ and simvastatin application on EPCs. (A) Controls (without TNF- $\alpha$ and simvastatin) showed a robust angiogenic ability and simvastatin had little effect on TNF- $\alpha$-induced degeneration (B) Silent information regulator type-1 (SIRT1) expression of each group was determined by western blot analysis and the TNF- $\alpha$-induced decrease in SIRT1 expression was significantly increased by high concentrations of simvastatin. ${ }^{*} \mathrm{P}<0.05$ and ${ }^{* *} \mathrm{P}<0.01$ compared to the control group, ${ }^{\#} \mathrm{P}<0.05$ versus the TNF- $\alpha$ group, $\mathrm{n}=3$ for each group for western blot analysis.

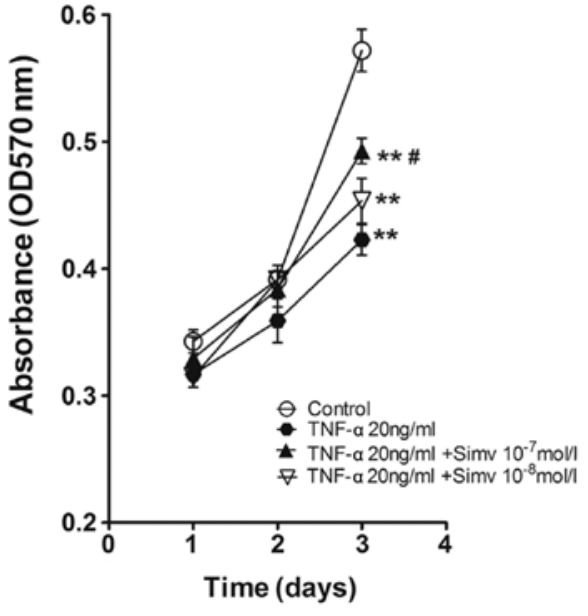

Figure 3. 3-(4,5-Dimethylthiazol-2-yl)-2,5-diphenyltetrazolium bromide (MTT) assay results showed the cell proliferation in three treatment groups. Data are expressed as mean $\pm \mathrm{SD},{ }^{* *} \mathrm{P}<0.01$ compared to the control group, ${ }^{~} \mathrm{P}<0.01$ versus tumor necrosis factor- $\alpha(\mathrm{TNF}-\alpha)$ group, $\mathrm{n}=5$ for each group.

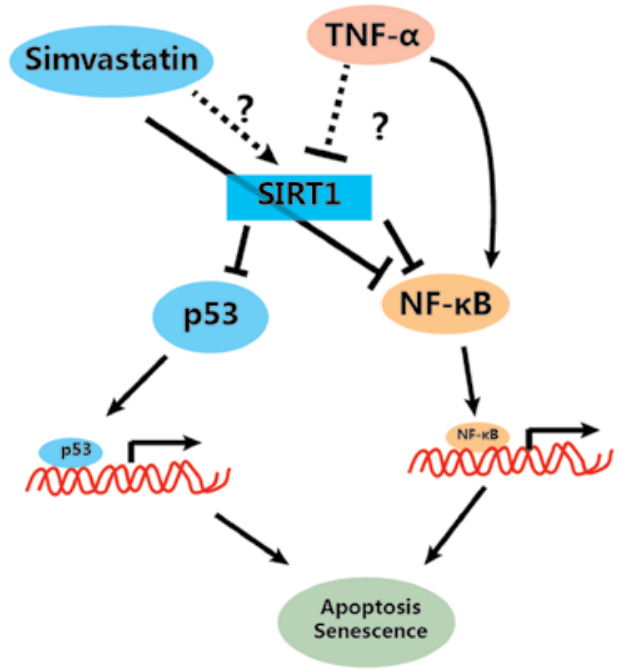

Figure 4. Proposed model for the mechanism of tumor necrosis factor- $\alpha$ (TNF- $\alpha$ ), simvastatin, silent information regulator type-1 (SIRT1), p53 and NF-кB signaling pathway involved in cell apoptosis and senescence. 
attenuate TNF- $\alpha$-induced apoptosis in EPCs (41). In this study, proliferation, apoptosis and angiogenesis of EPCs co-cultured with TNF- $\alpha$ and simvastatin were examined. We found that simvastatin exerts a mild anti-apoptotic effect on EPCs treated with TNF- $\alpha$ and that it enhances proliferation of EPCs that were previously inhibited by TNF- $\alpha$ incubation (Fig. 3). We found no effect of simvastatin treatment on the restoration of angiopoiesis (Fig. 2).

SIRT1 was originally identified as a nuclear protein that deacetylates proteins, contributing to cell regulation. Increasing SIRT1 allows for greater cell survival, particularly during periods of stress that usually trigger apoptosis. This occurs through regulation of the activity of several proteins, including FOXO, p53 and Ku70, all of which are involved in apoptosis or the initiation of cell repair (42-44). SIRT1 is located in the nucleus and translocated into the cytoplasm in response to hydrogen peroxide. This translocation results in an increased sensitivity to apoptosis (45). TNF- $\alpha$ is the prototypical member of a family of cytokines that also includes FasL, CD40L, and TRAIL. TNF- $\alpha$ is a potent inducer, which triggers inflammation, apoptosis, differentiation, and cell activation. TNF- $\alpha$ is found in the extracellular matrix, endothelium, and vessel walls of fibro-vascular tissue of proliferative diabetic retinopathy (46). Although SIRT1 levels can alter as a result of TNF- $\alpha$ exposure, its effects may differ depending on cell type, concentration, and time course. For instance, Wang et al (47) found that SIRT1 was highly expressed in the nucleus of vascular adventitial fibroblasts (VAFs) and translocated into the cytoplasm in response to TNF- $\alpha$. Dvir-Ginzberg et al (48) also found that SIRT1 expression was reduced in human chondrocytes that had been stimulated with TNF- $\alpha(50 \mathrm{mg} / \mathrm{ml})$ for $24 \mathrm{~h}$. Conversely, results of a recent study showed that the expression levels of SIRT1 mRNA and protein were markedly increased in vascular smooth muscle cells (VSMCs) treated with TNF- $\alpha$ at concentrations of 30 and $50 \mathrm{mg} / \mathrm{ml}$ for $8 \mathrm{~h}$ (49). Similarly, we found that TNF- $\alpha$ reduced SIRT1 protein expression levels in EPCs in a concentration- and time-dependent manner (Fig. 1). Our results have shown that the ability of angiopoiesis and proliferation of EPCs was markedly inhibited by TNF- $\alpha$. This conclusion was based on our data, which showed that incubation of EPCs with TNF- $\alpha$ significantly increased the percentage of apoptotic EPCs and simultaneously decreased the expression of SIRT1 (Fig. 2). Thus, we conclude that SIRT1 is involved in TNF- $\alpha$-induced apoptosis in EPCs.

However, the molecular mechanism through which statins exert their anti-apoptotic effect is unclear. Although we found that the expression of SIRT1 can be decreased by TNF- $\alpha$ and increased by simvastatin, additional experiments are required to identify the molecular mechanism between statins, SIRT1, and TNF- $\alpha$. Based on our results and the available literature, we have proposed a model demonstrating the role of simvastatin in apoptosis of EPCs (Fig. 4). We suggest that simvastatin inhibits cell apoptosis, in part, via the elevation of SIRT1. This elevation consequently inactivates NF- $\kappa \mathrm{B}$ activity by decreasing its acetylation state (NF- $\kappa \mathrm{B}-\mathrm{Ac})$. Additionally, simvastatin may inhibit NF- $\kappa \mathrm{B}$ activity directly, as has been previously reported in the literature $(50,51)$. Moreover, simvastatin-dependent SIRT1 increases could also decrease the activity of p53 by decreasing its acetylation, thus inhibiting the p53-dependent apoptosis.
In summary, we have shown that simvastatin plays an important role in the TNF- $\alpha$-induced apoptosis of EPCs and that this protection may involve SIRT1. These findings provide new evidence for the anti-inflammatory role of statins, which surpass their known effects on cholesterol metabolism.

\section{Acknowledgements}

This study has been supported by the Key Subject Construction of The First Affiliated Hospital of Jinan University, China.

\section{References}

1. Rouhl RP, van Oostenbrugge RJ, Damoiseaux J, Tervaert JW and Lodder J: Endothelial progenitor cell research in stroke: a potential shift in pathophysiological and therapeutical concepts. Stroke 39: 2158-2165, 2008.

2. Decano JL, Moran AM, Giordano N, Ruiz-Opazo N and Herrera VL: Analysis of CD45- [CD34+/KDR+] endothelial progenitor cells as juvenile protective factors in a rat model of ischemic-hemorrhagic stroke. PLoS One 8: e55222, 2013.

3. Huang H, Huang F and Huang JP: Transplantation of bone marrow-derived endothelial progenitor cells overexpressing Delta-like-4 enhances functional neovascularization in ischemic myocardium. Mol Med Rep 8: 1556-1562, 2013.

4. Thal MA, Krishnamurthy P, Mackie AR, et al: Enhanced angiogenic and cardiomyocyte differentiation capacity of epigenetically reprogrammed mouse and human endothelial progenitor cells augments their efficacy for ischemic myocardial repair. Circ Res 111: 180-190, 2012.

5. Patschan D, Hildebrandt A, Rinneburger J, et al: The hormone melatonin stimulates renoprotective effects of 'early outgrowth' endothelial progenitor cells in acute ischemic kidney injury. Am J Physiol Renal Physiol 302: F1305-F1312, 2012.

6. Bouchentouf M, Forner K, Cuerquis J, et al: A novel and simplified method of culture of human blood-derived early endothelial progenitor cells for the treatment of ischemic vascular disease. Cell Transplant 20: 1431-1443, 2011.

7. Głowińska-Olszewska B, Luczyński W and Bossowski A: [Endothelial progenitor cells as a new marker of endothelial function with respect to risk of cardiovascular disorders]. Postepy Hig Med Dosw (Online) 65: 8-15, 2011 (In Polish).

8. Shantsila E, Watson T and Lip GY: Endothelial progenitor cells in cardiovascular disorders. J Am Coll Cardiol 49: 741-752, 2007.

9. Sun JY, Zhai L, Li QL, et al: Effects of ACE inhibition on endothelial progenitor cell mobilization and prognosis after acute myocardial infarction in type 2 diabetic patients. Clinics (Sao Paulo) 68: 665-673, 2013.

10. Sandri M, Beck EB, Adams V, et al: Maximal exercise, limb ischemia, and endothelial progenitor cells. Eur J Cardiovasc Prev Rehabil 18: 55-64, 2011

11. Aicher A, Heeschen C, Sasaki K, Urbich C, Zeiher AM and Dimmeler S: Low-energy shock wave for enhancing recruitment of endothelial progenitor cells: a new modality to increase efficacy of cell therapy in chronic hind limb ischemia. Circulation 114: 2823-2830, 2006.

12. Jiménez-Navarro MF, González FJ, Caballero-Borrego J, et al: [Coronary disease extension determines mobilization of endothelial progenitor cells and cytokines after a first myocardial infarction with ST elevation]. Rev Esp Cardiol 64: 1123-1129,2011 (In Spanish).

13. Bonello L, Harhouri K, Baumstarck K, et al: Mobilization of CD34+ KDR+ endothelial progenitor cells predicts target lesion revascularization. J Thromb Haemost 10: 1906-1913, 2012.

14. Kim JY, Park YJ, Kim KJ, Choi JJ, Kim WU and Cho CS: Osteoprotegerin causes apoptosis of endothelial progenitor cells by induction of oxidative stress. Arthritis Rheum 65: 2172-2182, 2013.

15. Chen J, Huang L, Song M, Yu S, Gao P and Jing J: C-reactive protein upregulates receptor for advanced glycation end products expression and alters antioxidant defenses in rat endothelial progenitor cells. J Cardiovasc Pharmacol 53: 359-367, 2009.

16. Skoog T, Dichtl W, Boquist S, et al: Plasma tumour necrosis factor-alpha and early carotid atherosclerosis in healthy middleaged men. Eur Heart J 23: 376-383, 2002. 
17. Ruan W, Xu JM, Li SB, Yuan LQ and Dai RP: Effects of down-regulation of microRNA-23a on TNF- $\alpha$-induced endothelial cell apoptosis through caspase-dependent pathways. Cardiovasc Res 93: 623-632, 2012.

18. Markelic M, Velickovic K, Golic I, et al: Endothelial cell apoptosis in brown adipose tissue of rats induced by hyperinsulinaemia: the possible role of TNF- $\alpha$. Eur J Histochem 55: e34, 2011.

19. Nystrom T, Nygren A and Sjoholm A: Increased levels of tumour necrosis factor-alpha (TNF-alpha) in patients with Type II diabetes mellitus after myocardial infarction are related to endothelial dysfunction. Clin Sci (Lond) 110: 673-681, 2006.

20. Speciale A, Canali R, Chirafisi J, Saija A, Virgili F and Cimino F: Cyanidin-3-O-glucoside protection against TNF- $\alpha$-induced endothelial dysfunction: involvement of nuclear factor- $\kappa \mathrm{B}$ signaling. J Agric Food Chem 58: 12048-12054, 2010.

21. Henrich D, Seebach C, Wilhelm K and Marzi I: High dosage of simvastatin reduces TNF-alpha-induced apoptosis of endothelial progenitor cells but fails to prevent apoptosis induced by IL-1beta in vitro. J Surg Res 142: 13-19, 2007.

22. Seeger FH, Haendeler J and Walter DH, et al: p38 mitogen-activated protein kinase downregulates endothelial progenitor cells. Circulation 111: 1184-1191, 2005.

23. Ziedén B and Olsson AG: The role of statins in the prevention of ischemic stroke. Curr Atheroscler Rep 7: 364-368, 2005.

24. Margaritis M, Channon KM and Antoniades C: Statins as regulators of redox state in the vascular endothelium: beyond lipid lowering. Antioxid Redox Signal 20: 1198-1215, 2014.

25. Zhu Y, Casey PJ, Kumar AP and Pervaiz S: Deciphering the signaling networks underlying simvastatin-induced apoptosis in human cancer cells: evidence for non-canonical activation of RhoA and Rac1 GTPases. Cell Death Dis 4: e568, 2013.

26. Piechota-Polanczyk A, Goraca A, Demyanets S, et al: Simvastatin decreases free radicals formation in the human abdominal aortic aneurysm wall via NF- $\kappa B$. Eur J Vasc Endovasc Surg 44: $133-137,2012$

27. Fuhrmeister J, Tews M, Kromer A and Moosmann B: Prooxidative toxicity and selenoprotein suppression by cerivastatin in muscle cells. Toxicol Lett 215: 219-227, 2012.

28. Hoffmann G, Breitenbücher F, Schuler M and EhrenhoferMurray AE: A novel sirtuin 2 (SIRT2) inhibitor with p53-dependent pro-apoptotic activity in non-small cell lung cancer. J Biol Chem 289: 5208-5216, 2014.

29. Nihal M, Ahmad N and Wood GS: SIRT1 is upregulated in cutaneous T-cell lymphoma and its inhibition induces growth arrest and apoptosis. Cell Cycle 13: 632-640, 2014

30. Hori YS, Kuno A, Hosoda R and Horio Y: Regulation of FOXOs and p53 by SIRT1 modulators under oxidative stress. PLoS One 8: e73875, 2013.

31. Kim S, Bi X, Czarny-Ratajczak M, et al: Telomere maintenance genes SIRT1 and XRCC6 impact age-related decline in telomere length but only SIRT1 is associated with human longevity. Biogerontology 13: 119-131, 2012.

32. Kok SH, Lin LD, Hou KL, et al: Simvastatin inhibits cysteine-rich protein 61 expression in rheumatoid arthritis synovial fibroblasts through the regulation of sirtuin-1/FoxO3a signaling. Arthritis Rheum 65: 639-649, 2013.

33. Ota H, Eto M, Kano MR, et al: Induction of endothelial nitric oxide synthase, SIRT1, and catalase by statins inhibits endothelial senescence through the Akt pathway. Arterioscler Thromb Vasc Biol 30: 2205-2211, 2010.
34. Dimitrova KR and Leitman IM: Intramyocardial transplantation of endothelial progenitor cells and erythropoietin: a new scope for the treatment of cardiovascular disease. J Surg Res 183: $550-552,2013$

35. Hu CH, Ke X, Chen K, Yang DY, Du ZM and Wu GF: Transplantation of human umbilical cord-derived endothelial progenitor cells promotes re-endothelialization of the injured carotid artery after balloon injury in New Zealand white rabbits. Chin Med J (Engl) 126: 1480-1485, 2013.

36. Liu P, Zhou B, Gu D, Zhang L and Han Z: Endothelial progenitor cell therapy in atherosclerosis: a double-edged sword? Ageing Res Rev 8: 83-93, 2009.

37. Du G, Zhou L, Ghang Q and Li Z: Inhibitory effect of simvastatin on replicative senescence of endothelial progenitor cells and its mechanism. J Jilin Univ (Medicine Edition) 39: 913-918, 2013.

38. Thum T, Fraccarollo D, Galuppo P, et al: Bone marrow molecular alterations after myocardial infarction: impact on endothelial progenitor cells. Cardiovasc Res 70: 50-60, 2006.

39. Tousoulis D, Oikonomou E, Siasos G and Stefanadis C: Statins in heart failure - with preserved and reduced ejection fraction. An update. Pharmacol Ther 141: 79-91, 2014.

40. Balakumar P, Kathuria S, Taneja G, Kalra S and Mahadevan N: Is targeting eNOS a key mechanistic insight of cardiovascular defensive potentials of statins? J Mol Cell Cardiol 52: 83-92, 2012.

41. Xu S, Zhao Y, Yu L, Shen X, Ding F and Fu G: Rosiglitazone attenuates endothelial progenitor cell apoptosis induced by TNF- $\alpha$ via ERK/MAPK and NF- $\kappa \mathrm{B}$ signal pathways. J Pharmacol Sci 117: 265-274, 2011.

42. Yuan H, Wang Z and Li L, et al: Activation of stress response gene SIRT1 by BCR-ABL promotes leukemogenesis. Blood 119: 1904-1914, 2012.

43. Huang PS, Son JH, Abbott LC and Winzer-Serhan UH: Regulated expression of neuronal SIRT1 and related genes by aging and neuronal $\beta 2$-containing nicotinic cholinergic receptors. Neuroscience 196: 189-202, 2011.

44. Jeong J, Juhn K, Lee H, et al: SIRT1 promotes DNA repair activity and deacetylation of Ku70. Exp Mol Med 39: 8-13, 2007.

45. Jin Q, Yan T, Ge X, Sun C, Shi X and Zhai Q: Cytoplasm-localized SIRT1 enhances apoptosis. J Cell Physiol 213: 88-97, 2007.

46. Kacimi R, Karliner JS, Koudssi F and Long CS: Expression and regulation of adhesion molecules in cardiac cells by cytokines: response to acute hypoxia. Circ Res 82: 576-586, 1998.

47. Wang W, Yan C, Zhang J, et al: SIRT1 inhibits TNF- $\alpha$-induced apoptosis of vascular adventitial fibroblasts partly through the deacetylation of FoxO1. Apoptosis 18: 689-701, 2013.

48. Dvir-Ginzberg M, Gagarina V, Lee EJ, Booth R, Gabay O and Hall DJ: Tumor necrosis factor $\alpha$-mediated cleavage and inactivation of SirT1 in human osteoarthritic chondrocytes. Arthritis Rheum 63: 2363-2373, 2011.

49. Zhang HN, Li L and Gao P, et al: Involvement of the p65/RelA subunit of NF-kappaB in TNF-alpha-induced SIRT1 expression in vascular smooth muscle cells. Biochem Biophys Res Commun 397: 569-575, 2010

50. Yang J, Huang C, Yang J, Jiang H and Ding J: Statins attenuate high mobility group box-1 protein induced vascular endothelial activation: a key role for TLR4/NF- $\mathrm{BB}$ signaling pathway. Mol Cell Biochem 345: 189-195, 2010.

51. Ahn KS, Sethi G and Aggarwal BB: Reversal of chemoresistance and enhancement of apoptosis by statins through downregulation of the NF- $\kappa$ B pathway. Biochem Pharmacol 75: 907-913, 2008. 